\title{
From quality management to quality improvement-structures, processes and outcomes
}

\author{
Simone Wesselmann ${ }^{1} \cdot$ Martin Burchardt ${ }^{2} \cdot$ Christoph Kowalski $^{1}$
}

Published online: 23 January 2021

(c) The Author(s), under exclusive licence to Springer-Verlag GmbH, DE part of Springer Nature 2021

The current topic issue of the World Journal is dedicated to 'Quality Management of Patients with Prostate Cancer Care', an issue that has drawn much attention in the past among patients, health care providers, and politicians.

Without knowledge of which potential management strategies are best suited for the individual patient, quality management needs to assure that treatment is based on current scientific knowledge. This includes care according to clinical guidelines and measurement of quality, structures, processes, and outcomes. The latter is particularly important since outcomes in prostate cancer (PCa) significantly depend on complex surgical/radio-therapeutical intervention, skills of the individual surgeon/radio-therapist, and the multidisciplinary team [1], as well as preparation of the intervention and immediate aftercare [2-4]. This is where Donabedian's [5] approach and its translation into quality indicators meet their limits-it is not only important that but also how something is done. Our knowledge of the impact of specific 'ingrediencies' to complex interventions is limited. Although numerous textbooks address operating skills, scientific-based guidelines are missing for surgical procedures such as radical prostatectomy (RP). One approach is to use observational data to identify where and why outcomes are superior and to potentially learn from exceptionally good performance [6,7].

Another approach to address the need of guidelines was taken by Butea-Bocu et al. [7] who analyzed a large cohort

Simone Wesselmann

wesselmann@krebsgesellschaft.de

Martin Burchardt

martin.burchardt@med.uni-greifswald.de

Christoph Kowalski

kowalski@krebsgesellschaft.de

1 Deutsche Krebsgesellschaft e. V., Kuno-Fischer-Street 8, 14057 Berlin, Germany

2 Universitatsklinikum Greifswald, Sauerbruchstraße street, 17475 Greifswald, Germany who presented in a rehabilitation clinic after RP. Their RP was either performed in a certified hospital according to the quality assuring criteria of the German Cancer Society or in a non-certified clinic [8]. Certified center patients presented with better oncological and functional outcomes (negative margins, continence, erectile dysfunction), a finding that is in line with previous studies for colorectal cancer $[9,10]$. However, this study does not explain which elements of treatment in certified units account for better results, but it suggests that investing in rigorous quality management contributes substantially to better outcomes.

Survival of localized PCa is significantly better than for many other cancers. At the same time, functional complications such as incontinence and erectile dysfunction following RP reduce quality of life substantially for many patients. Knowledge of differences across sites or surgeons that lead to such impairment is critical. Long-term complications can be reported ideally by the patient himself, completing scientifically accepted patient-reported outcome measures (PROMs). Involving patient advocates, the International Consortium for Health Outcomes Measurement (ICHOM) developed a standard data set for localized PCa that includes the measurement of PROMs [11] using the EPIC-26 questionnaire [12]. This standard is implemented into practice in a large registry [13], including patients from 15 countries and 220 clinical sites. The intention is to compare and reduce variations in $\mathrm{PCa}$ care. Comparing outcomes across countries requires that results are measured the same way. Sibert et al. therefore assessed the psychometric validity of the German version of the EPIC-26 [14]. The authors analyzed data from the first enrolled 3094 patients [15]. Their analysis proofs that the German version of the EPIC-26 is suitable for measuring functional outcomes and psychometric properties, in line with the original American version and other translations.

When quality is compared across providers, different populations need to be analyzed because different patients are at various risks for impaired outcomes, independent of the 
treatment they receive. Such "case mix-adjustment" requires knowledge about the risk-factors. Following a rather fundamental research approach, Roth et al. [16] identified clinical and sociodemographic correlates of pretherapeutic EPIC-26 domain scores. Applying an advanced statistical approach, they related lesser educational attainment and more severe disease to impaired function in four of the five EPIC-26 domain scores. While the latter is little surprising, educational attainment is still not considered in many studies.

While the first three contributions to this topic issue are original articles analyzing data from German patients, the remainder of the issue widens the scope to a European perspective. Tit Albreht, leader of the ongoing European Commission Cancer Joint Action iPAAC reviewed existing European national cancer control plans (NCCPs) and accompanying documents to search for PCa screening and management. He finds that quality is not a prominent issue in NCCPs and that specifically "prostate cancer is poorly represented and insufficiently addressed, in particular with respect to screening, but also in after-care and survivorship challenges" [17].

When literature does not guide, local initiatives are required to apply quality management principles that proved successful elsewhere. Such initiative is reported by Noris Chiorda et al. [18] who implemented the requirements of the German Cancer Society in the Fondazione IRCCS Instituto Nazionale dei Tumori in Milan, Italy. They give an honest account of difficulties that must be overcome to implement ideas developed for other health care systems and highlight the potential that comes with such an effort. One of these potentials is the comparison of the quality of sites using identical indicators across countries. This is described by Griesshammer et al. [19] who present a comparison of quality indicator results between 114 Prostate Cancer Centers certified in German and those nine centers certified in other countries under the guidance of the European Cancer Centers (ECCs) program. Results suggest an overall improvement of quality measures over time. Although certification is achievable for units outside Germany, country specifics need to be considered.

From a public health perspective, quality management is a key to improve PCa care for the entire population in need. Quality management needs to be advanced and promoted by professionals plus patients as well as based on scientific findings. It is an important tool for self and external outcome control and future improvement of results.

\section{References}

1. Holmes A, Kelly BD, Perera M et al (2020) A systematic scoping review of multidisciplinary cancer team and decision-making in the management of men with advanced prostate cancer. World $\mathbf{J}$ Urol. https://doi.org/10.1007/s00345-020-03265-1

2. Lenart S, Berger I, Böhler J et al (2020) Ideal timing of indwelling catheter removal after robot-assisted radical prostatectomy with a running barbed suture technique: a prospective analysis of 425 consecutive patients. World J Urol 38:2177-2183. https://doi. org/10.1007/s00345-019-03001-4

3. Knipper S, Hagedorn M, Sadat-Khonsari M et al (2020) Comparison of intra- and postoperative analgesia and pain perception in robot-assisted vs. open radical prostatectomy. World J Urol 38:1451-1457. https://doi.org/10.1007/s00345-019-02938-w

4. Kowalewski KF, Hendrie JD, Nickel F et al (2020) Prophylactic abdominal or retroperitoneal drain placement in major urooncological surgery: a systematic review and meta-analysis of comparative studies on radical prostatectomy, cystectomy and partial nephrectomy. World J Urol 38:1905-1917. https://doi. org/10.1007/s00345-019-02978-2

5. Donabedian A (1966) Evaluating the quality of medical care. Milbank Mem Fund Q 44(Suppl):166-206

6. Campbell NC, Murray E, Darbyshire J, et al (2007) Designing and evaluating complex interventions to improve health care. BMJ 334:455-459. https://doi.org/10.1136/bmj.39108.379965.BE

7. Butea-Bocu MC, Müller G, Pucheril D et al (2020) Is there a clinical benefit from prostate cancer center certification? An evaluation of functional and oncologic outcomes from 22,649 radical prostatectomy patients. World J Urol. https://doi.org/10.1007/s0034 5-020-03411-9

8. Kowalski C, Ferencz J, Albers P et al (2016) Quality assessment in prostate cancer centers certified by the German Cancer Society. World J Urol 34:665-672. https://doi.org/10.1007/s0034 5-015-1688-z

9. Völkel V, Draeger T, Gerken M et al (2019) Langzeitüberleben von Patienten mit Kolon-und Rektumkarzinomen: Ein Vergleich von Darmkrebszentren und nicht zertifizierten Krankenhäusern. Gesundheitswesen 81:801-807. https://doi. org/10.1055/a-0591-3827

10. Trautmann F, Reißfelder C, Pecqueux M et al (2018) Evidencebased quality standards improve prognosis in colon cancer care. Eur J Surg Oncol 44:1324-1330. https://doi.org/10.1016/j. ejso.2018.05.013

11. ICHOM-International Consortium for Health Outcomes Measurement (2016) Colorectal cancer data collection reference guide

12. Szymanski KM, Wei JT, Dunn RL, Sanda MG (2010) Development and validation of an abbreviated version of the expanded prostate cancer index composite instrument for measuring healthrelated quality of life among prostate cancer survivors. Urology 76:1245-1250. https://doi.org/10.1016/j.urology.2010.01.027

13. Evans SM, Millar JL, Moore CM et al (2017) Cohort profile: the TrueNTH global registry-an international registry to monitor and improve localised prostate cancer health outcomes. BMJ open 7:e017006. https://doi.org/10.1136/bmjopen-2017-017006

14. Sibert NT, Dieng S, Oesterle A et al (2019) Psychometric validation of the German version of the EPIC-26 questionnaire for patients with localized and locally advanced prostate cancer. World J Urol. https://doi.org/10.1007/s00345-019-02949-7

15. Kowalski C, Roth R, Carl G et al (2020) A multicenter paperbased and web-based system for collecting patient-reported outcome measures in patients undergoing local treatment for prostate cancer: first experiences. J Patient Rep Outcomes 4:56. https://doi. org/10.1186/s41687-020-00224-7

16. Roth R, Dieng S, Oesterle A et al (2020) Determinants of selfreported functional status (EPIC-26) in prostate cancer patients prior to treatment. World J Urol. https://doi.org/10.1007/s0034 5-020-03097-z 
17. Albreht T (2020) Quality management in (prostate) cancer care: what do European cancer control plans tell us? World J Urol. https ://doi.org/10.1007/s00345-020-03258-0

18. Noris Chiorda B, Zollo F, Magnani T et al (2019) How to implement the requirements of a quality assurance system for prostate cancer. World J Urol. https://doi.org/10.1007/s00345-019-03024 $-\mathrm{X}$

19. Griesshammer E, Adam H, Sibert NT, Wesselmann S (2020) Implementing quality metrics in European Cancer Centers
(ECCs). World J Urol. https://doi.org/10.1007/s00345-020-03165 $-4$

Publisher's Note Springer Nature remains neutral with regard to jurisdictional claims in published maps and institutional affiliations. 